\title{
Implementing optics courses in dual engineering university programs: challenges and perspectives
}

Janine Brennförder, Cornelius Hahlweg

Janine Brennförder, Cornelius Hahlweg, "Implementing optics courses in dual engineering university programs: challenges and perspectives," Proc. SPIE 10741, Optics Education and Outreach V, 1074104 (14 September 2018); doi: $10.1117 / 12.2322360$

EDIE Event: SPIE Optical Engineering + Applications, 2018, San Diego, California, United States 


\title{
Implementing optics courses in dual engineering university programs: challenges and perspectives
}

\author{
Janine Brennförder and Cornelius Hahlweg \\ bbw Hochschule - University of Applied Sciences \\ Leibnizstrasse 11-13, D-10625 Berlin, Germany
}

\begin{abstract}
There are a few barriers to justify the implementation of optics courses into the tight time schedule of a dual engineering university program. The integration of optics into the classic occupational areas of electrical- and communication engineers is ambitious. Between optics and electrics, there are many overlapping contents and correlations. Most companies want fast highly specialized workers but they will not recognize that the most important skill of engineers is their ability to think outside the box. The process of engineering is not to follow algorithms and processes. Their purpose is to develop unique and working solutions that are unable to solve for other specialists. This is because they can see the big picture. To develop this ability it is neccessary to teach them the connections between different fields and to show them the possibilities of science.

Only engineers with that far-sightness are able to handle the proceeding digitalization of their business ant to stay productive and contemporary. Most of their work e.g. calculations of construction parts can be solved by standartized algorithms and programs but their real work to think about solutions can never be automatized. Those solutions can be devised with parts of theoretical foundations of optics.
\end{abstract}

Keywords: electrical engineering, dual program, optics, personal stress and pressure, education, smartphone usage, depression

\section{Introduction}

The paper is dedicated to the teaching of optics in the social aspects and organizational challenges within a dual engineering university program. Students in those dual studies are in double pressure. They "are integrated not only in their university program, but also in an extremely demanding professional environment. "1 That means that those young students which come normally directly after their graduartion into the dual university programs are exposed to a new environment full of stress and an unknown athmosphere. These circumstances are hard to handle for the lecturers.

Additionally to the stressed students it is also hard to handle with the employers of the students for the university. They demand high quality and highly qualified degree holders after the completion of the university course. The employers sometimes want to change some contents of subjects or need to substract sometimes students from a lecture. It is also obligatory that the students need to finish a whole semester with the associated subjects and exams within three months.

In our case we will analyze young students and their studies of electrical engineering with the specialization of train control systems at the bbw Hochschule ${ }^{2}$ with the focus on optics courses. The paper is a follow-up on a formerly written paper about optics and optronics in university courses for officers of the federal armed forces. ${ }^{1}$ There are certain paralles between the officers at the military university and dual students. The both of them are studying under circumstances where they are guided from a higher instance (authorized officer or employer) and need to work parallel to their studies.

Further author information: CH: cornelius.hahlweg@bbw-hochschule.de, JB: janine.brennfoerder@hotmail.com

Optics Education and Outreach V, edited by G. Groot Gregory, Proc. of SPIE Vol. 10741, 1074104

(C) 2018 SPIE · CCC code: $0277-786 \mathrm{X} / 18 / \$ 18 \cdot$ doi: $10.1117 / 12.2322360$ 


\section{Dual studies in Germany}

The recruiting of young and qualified engineers with special knowledge in e.g. special railway components is difficult. Companies need to train their new colleagues in those special fields and integrate them into the departments. This process is expensive and time-consuming. To solve that issue some companies cooperate with different universities to offer dual university programs. Students in dual university programs are employed by the company that has chosen to assume the student. They are working and studying in three month circles which are self contained in their educational aspect. For example the student begins with his first university stage. In those three months he needs to be teached the whole knowledge of a semester and to pass the examinations.

After the university stage there follows the company stage where the student is intoduced to the department and the projects where he can support the other employees. In those stages the student is about to get his first work experience and has to write a report about his practices. That report is part of an exam at the university. After completing six university stages and five working stages the student has to write his bachelor thesis and is after passing that exam a degree holder that can work full-time for his company. Figure 1 shows the timeline of a dual engineering university program.

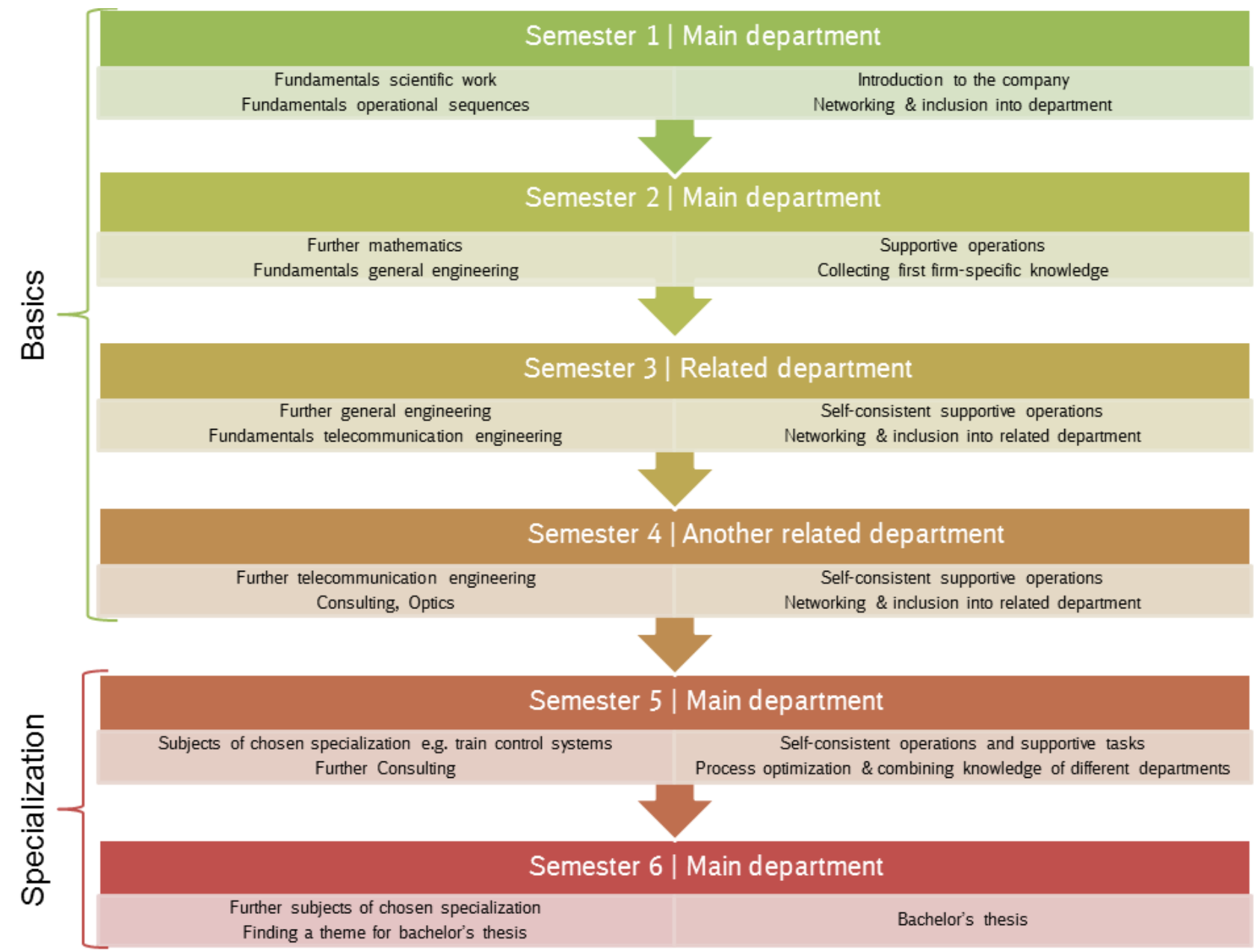

Figure 1. Timeline of a dual engineering university program. University part is on the left side, company part is on the right side. 


\section{Curriculum}

For each field of study and specialization there are different courses to teach. In this paper is the dual study of electrical engineering with specialization train control systems at the bbw Hochschule the central theme. Table 1 gives a review about all subjects that are part of the dual university course. Students have to complete them and can't choose other subjects like in normal university courses.

\begin{tabular}{|c|c|c|c|}
\hline semester 1 & $\begin{array}{l}\text { material science, mechanical design } \\
\text { fundamentals of scientific work } \\
\text { physics } \\
\text { basic principles of operation and law } \\
\text { math for engineers I }\end{array}$ & semester 2 & $\begin{array}{l}\text { project management } \\
\text { computer engineering } \\
\text { electrical engineering I } \\
\text { math for engineers II }\end{array}$ \\
\hline & theory-to-practice transfer report & & theory-to-practice transfer project \\
\hline \multirow[t]{2}{*}{ semester 3} & $\begin{array}{l}\text { signal and system theory } \\
\text { electrical engineering II } \\
\text { automatic control engineering } \\
\text { digital electronics }\end{array}$ & semester 4 & $\begin{array}{l}\text { computer aided design } \\
\text { consulting engineer } \\
\text { electrical drives } \\
\text { high-frequency technology } \\
\text { technical english } \\
\text { optics }\end{array}$ \\
\hline & theory-to-practice transfer report & & theory-to-practice transfer project \\
\hline \multirow[t]{2}{*}{ semester 5} & $\begin{array}{l}\text { computer aided engineering } \\
\text { communication networks } \\
\text { rail vehicle technics } \\
\text { train control systems I } \\
\text { engineering standarts }\end{array}$ & semester 6 & $\begin{array}{l}\text { train control systems II } \\
\text { traffic control systems }\end{array}$ \\
\hline & theory-to-practice transfer report & & bachelor's thesis \\
\hline
\end{tabular}

Table 1. Subjects of the dual university course in electrical engineering with specialization train control systems at the bbw Hochschule

The first four semesters are part of the basics studies. In this case electrical engineering. Most of the subjects are also part of a communicational engineering university course. The fifth and the sixth semesters contain the subjects of the specialization. After three months of each semester are following three months in the company. In this time the students are fully aviable for their employer but they have to write a report about a self-chosen topic in which they analyze how any subject they've already had fits into their working tasks.

In the fourth semester the subject optics is teached. The most earlier subjects lead to a better expertise that is helpful to understand and get the idea behind some optics concepts like the laws of reflection that has been teached in transmission technology or some basic principles that have been told in physics. Optics is fundamental for the comprehension of being an engineer and is the junction of many other subjects. For a student it is much easier to understand the law of reflection when it is shown with light or the prinicple of interference.

\section{Problems and challenges}

This section will outline an overview of the challenges with dual programs but most of them are also relevant for common degree programs. The most students have graduated from their highschools and aged between 18-22 years. They applied to their dual study a year before it starts and they don't know what they will learn or what their function will be. Those young people need to sign a contract that binds them to the employer for 3 years of their study and in common cases also for a few years afterwards. This may sound attractive and is a safe way for their career entry but they don't even know what is coming next and what they will have to do.

\section{Students perception}

The university programs are usually starting in october. In the first week of october the students are introduced to their departments and some general informations and tasks of their employer. Afterwards they are going to 
the university for the next months. The first few weeks at the university are difficult for the young students because they are exposed to a new environment and new methods of teaching and learning. With all theese new impressions some of them are overstrained. After a few weeks they have to write their first examinations. Because of the tight time schedule of three month lasting semesters and working stations it is hard to let some ideas mature and get the gist of some subjects.

\section{Statements to the university}

Many students are asking the question "Why do we have to do that at all?" about a few modules. Table 2 shows some thoughts of those students about some subjects. The whole university program is designed to lay down the foundation for later subjects of the specialization but the students don't understand why they need to learn for early-stage subjects like materials technology. They don't directly need them at work so they are not motivated to learn for them. That approach is problematical because when they haven't understood the basics they won't understand further subjects which need some basic understanding of modules teached in earlier stages of the university program. The students feel overstrained and stressed which causes them to loose their concentration and motivation that they need to understand the knowledge of their specialisation.

\begin{tabular}{|l|c|c|l|}
\hline Module & need at work & capable & student's conclusion \\
\hline Mathematics I & - & $\mathrm{x}$ & $\begin{array}{l}\text { I don't need that and I already know how to do that } \\
\text { - no need to learn that subject }\end{array}$ \\
\hline Mathematics II & - & - & $\begin{array}{l}\text { I don't need that and it's too hard to understand } \\
\text { because they haven't teached me the basics - no need } \\
\text { to learn that subject }\end{array}$ \\
\hline Materials Technology & - & $\mathrm{x}$ & I don't need that - no need to learn that subject \\
\hline Electrical Engineering I & - & - & $\begin{array}{l}\text { I don't need that and I don't understand that be- } \\
\text { cause they haven't teached me how to calculate the } \\
\text { basics and how theese materials work - no need to } \\
\text { learn that subject }\end{array}$ \\
\hline Electrical Engineering II & $\mathrm{x}$ & - & $\begin{array}{l}\text { I don't understand that because they haven't teached } \\
\text { me the basics - I'm overstrained and stressed }\end{array}$ \\
\hline Train control systems & $\mathrm{x}$ & $\mathrm{x}$ & $\begin{array}{l}\text { I don't understand that in depth because they } \\
\text { haven't teached me how electrical components work }\end{array}$ \\
\hline
\end{tabular}

Table 2. Capabilities of different modules for dual students

Students with lack of motivation are more likely to distract other students or distract themselfes. In our all-time aviable demanding society most of those students are chatting via messengers with other people or browsing through newsfeeds and their social media accounts. Even if the topics are relevant or easy to understand it is hard for the distracted students to follow the lecturer. When it comes to more technical insight topics the students look up from their phones and can't understand anything because they haven't payed attention to earlier subjects. Because they are overstrained now they are making the lecturer to be responsible for their lack of previous knowledge and continue to keep themselves occupied with their phones.

This leads to more extensive problems: The students are unable to combine the knowledge that is mediated in their university program. That means that they need to get told by the lecturer every conclusion and every step in eacht subject, process and experiment. The students are disabled to think by themselves which causes them to loose the most important ability of engineers and scientists: To think by themselves about solutions nobody else can provide. But not only the ability to think outside the box is getting lost.

\section{Statements to the employer}

Because the students are frustrated from their studies and the employer is asking for feedback the students tell the employer some subjective proposals. Because of the lack of communitcation between the universities and the employer it is hard to differ between well-grounded reasons of poor teaching and the mixture between the frustration of the student and factoids. This causes some misunderstandings and criticism between the employer 
and the university. Table 3 shows some feedback of the employers that were caused by students who tried to explain which problems they see at the university.

\begin{tabular}{|l|l|}
\hline Employers statement & Reason and Explanation \\
\hline It is hard to hear the lecturer acoustical. & $\begin{array}{l}\text { The students choose to seat in the back-row because it is easier to } \\
\text { play with their phones when the lecturer can't see what they are } \\
\text { doing. }\end{array}$ \\
\hline $\begin{array}{l}\text { Substitution tasks and theory-to- } \\
\text { practice transfer reports are taking a } \\
\text { huge amount of time at work. Because } \\
\text { of that we can't teach the students } \\
\text { enough. }\end{array}$ & $\begin{array}{l}\text { Students told the employer that the university wants them to do } \\
\text { their reports and university tasks at work. This is caused by a lack } \\
\text { of communication between the employer and the university. The } \\
\text { reports should handle some topics from the affairs which should } \\
\text { cause that the students occupy themselves more in depth with their } \\
\text { topics. }\end{array}$ \\
\hline $\begin{array}{l}\text { The specialization subjects need to be } \\
\text { teached earlier. The students come to } \\
\text { their workplace and don't even know } \\
\text { what we do. }\end{array}$ & $\begin{array}{l}\text { The employer wants to educate young people within a complex field } \\
\text { of work. Therefore the students need to know the basics of e.g. } \\
\text { electrical engineering. Even if the specialization is the desired field } \\
\text { the basics need to be teached. }\end{array}$ \\
\hline
\end{tabular}

Table 3. Statements of the employer in matters of students feedback about the university course.

These are only a few statements of the employers. The conclusion about those statements is that the students abuse the lack of communication between the employer and the university to get profits e.g. more free time or excuses for poor results at work.

\section{Lecturers perception}

It is pretty hard for the lecturer to provide all the knowledge to distracted students. That means that they can't teach the whole workload of knowledge to the students. The conclusion about that is easy: the exams need to be easier and contain less argumentational questions. Within normal university programs it is easier to provide some extra knowledge in other courses but in dual studies the time schedule is too tight and the employers of the students set the university under pressure that the students will finish their university program within 3 years. When the employer recognizes too much complaints about the university they will send their students to other universitys which means a huge loss in money and reputation for the institution. To deal with that pressure sent by the employers and the distracted students is a monumental challenge.

Some students are asking their lecturers to upload all documents and lecture notes before the lecture starts. Their justification for that is that they don't need to take notes within the lecture. This may sound good and the students are able to pay more attention to the academic but what really happens is the opposite. Students are even more unmotivated to follow the instructions and explanations. They are in the oppinion that everything that's important is written in the scripts and all they are listening to is the lecturers "this topic is relevant for the exam".

Another critical fact about the dual university program is, that the students have to successfully complete the studies. Their contract with their employer contains sometimes passages like money-refunding when a student won't pass some exams or when they abandon their studies. The young students need to know by a young age that they want to study the defined subject. There is nearly no possibility to change into another subject. When a student recognizes that he can't imagine himself in the future with that job it will lead to a huge lack of motivation and sometimes to depression.

\section{The optics course as multidisciplinary project}

Obviously an electrical engineering course is predestinated for the integration of an optics course. In terms of railway and transport technology, motivation is found in optical traffic signalling technology as well as in optical transmission. As such, these subjects could be part of transmission/ communication technology and train control systems according to table 1 . As a separate module in the 4 th semester, such a course offers the 
opportunity to combine main outcomes of several important modules found in earlier semesters, from material science over higher math, electrical engineering, physics, mechanical design, up to electromagnetic field and wave theory, which are part of RF/ high frequency technology, intentionally held in parallel for maximum synergy.

Due to the complexity of the subject, the matter is imparted iteratively with increasing degree of difficulty, starting with fractions from material science, basic geometrical optics and human perception, leading to wave problems, opto-electronics, applied camera systems and finally the design of complex multilens systems. More than 50 percent of the lessons are dedicated to practical work in the lab. The lab experiments are used to define tasks for team based projects, resulting in presentations and written scientific/technical report. The latter substitute a written theoretical exam.

These demanding sessions usually result in an altered perception of subject which were found useless only one semester before, see perception table 2. The substitution of written exams by extended technical reports reduces the susceptibility for so called bulimic learning* but - instead - demands an intense look into the several subjects.

As a result, in subsequent modules like Computer Aided Engineering, a selection of additional topics for student projects - like digital image processing or optical communication - might be chosen from. Further, these subjects are to be found again in some of the student's bachelor theses, which usually happens when the perception of the requirements of their departments finally meet the reality of the university courses.

\section{Smart phone use as a challenge}

Although the present paper should be focussed on optics education, it seems appropriate to give some remarks on the use of smartphone technology in general educational situations. Among teachers and lecturers certain observations on the change of student behaviour and learning attitude is discussed. On one hand, there is the exploding tendency of collecting information without assimilation. We find typical statements in table 3 and under lecturers perception, when lecture notes are demanded to avoid the traditional manual notes. This tendency is obviously linked to a substitution of true personal insight by the sensation of successfully finding an answer the words of the answer - by searching the internet as fast as possible.

As a result, the use of real textbooks is not trained and therefore partially unknown as a form of research and learning. By the end of the first decade of the new century internet research was mainly dependent on the use of a PC, its typical size and supply requirements. The advent of the second decade, already starting with the introduction of the iPhone in 2007 and the rollout of 4G technology in $2009^{3}$ a full-fledged internet use became part of the everyday situation, and naturally of the typical education situation. Around this time a real time peer-to-peer communication instead of the limited short message became fashionable and a partial substitute for a real social environment.

A graphical timeline could easily illustrate, that in parallel a generation of people, grown up completely in the age of internet and mobile communication devices, would enter the university scene. In 2018 the typical young student does not have any experience of a world without mobile devices and internet. Today's typical classroom situation involves the permanent smartphone usage of a high percentage of the students, mainly for communication purposes out of the context of the lesson, but also for information retrieval, often to proof what was just said by the lecturer, often accompanied by showing and discussing a clear preference for unreliable sources. Another observation is the sudden switch from concentration and attention to a apparent relaxation phase with intense phone use.

There are certain cues that behavioural changes, unhappiness and depression are connected to smartphone use. ${ }^{4}$ Indeed, there seems to be an increasing number of depression related cases, which should be subject to further investigation on its own.

\footnotetext{
${ }^{*}$ The expression refers to the idea of massive knowledge consumption, just to be completely emptied out during the exam.
} 
Solutions like the ban of smartphones by decree demand control schemes, which in principle would require measurement technology in the class room. A less restrictive solution is described in, ${ }^{5}$ where smart phone breaks are suggested.

\section{Conclusion and outlook}

It is hard to handle with students that are under double pressure from their employer and the university courses and exams. They are having always the upper hand because they can charge problems directly to their employer who pays the university to teach the students. Because of that, the lecturers need to fulfill nearly every wish of the students e.g. uploading lecture notes early or precising the contens of exams. After the students have written their exams they are going for three months to work for their employers and have nothing much to do with their studies. In this time they are doing practice work and forget some of their learning matter.

Under these circumstances it is hard to educate young people to capable academics. It is necessary to develop new and alternative ideas to teach the students the subjects, even if they are not fully interested in that matter. The exams need to be compact enough that every student can pass them. That means, that the students are learning intensive for the exams but forget everything they've learned after they've finished them.

To avoid behavior pattern like that there are a few possibilities. One of them is to let the students write papers as substitute for the examinations. For writing a paper they need to grapple themselves in depth with the chosen topic. They will learn sustainable and eventually they will find some interest within the topic and will occupy themselves with more in-depth information. The topics for the papers can be chosen together with the employer so the students see some sense in the subject which causes them to stay motivated.

Maybe universities should think about their conventional methods of instruction and change the conventional way of teaching content to an unconventional type of university course. They need not only to overthink their teaching aids e.g. the exchange of blackboards with smart boards but also about the way of introducing young people to academical degrees. The young people are not only interested in earning money and having a safe working place, they are interested in individual fulfilment and exploring the world. To stay in time for young people who want to reach academical qualifications the universities need to fit better into the alternative and modern concepts of the new generations.

All in all the universities need to work together more closely with the employers to keep the students motivated and interested in working for the companies. The lecturers need to understand why the young generations are so easily distracted by their phones and need to adjust their methods of teaching complicated topics to the students. But also the students have to be told that it can't always be easy to study and learn for the examinations. Maybe all sides need to have more appreciation for each other and to understand that the conventional methods of instruction won't always work within an unconventional system.

\section{REFERENCES}

1. C. Hahlweg and H. Rothe, "Optics and optronics in university courses for officers of the federal armed forces special curricula and hands-on lessons vs. academic requirements," Optics Education and Outreach IV Proc. SPIE. 9946, 2016.

2. BBW Hochschule, "Dualer Studiengang Elektrotechnik mit der Spezialisierung Leit- und Sicherungstechnik," https://www.npr.org/sections/health-shots/2017/08/07/542016165/how-smartphones-are-making-kidsunhappy? $t=1532525042518,032018$.

3. Unknown, "Teliasonera First To Offer 4G Mobile Services," The Wall Street Journal: $\quad$ https://www.wsj.com/articles/BT-CO-20091214-707449 , $122009 . \quad$ archived: https://web.archive.org/web/20100114110530/http://online.wsj.com/article/BT-CO-20091214-707449.html.

4. A. Cornish, "How Smartphones Are Making Kids Unhappy," National Public Radio: https://www.npr.org/sections/health-shots/2017/08/07/542016165/how-smartphones-are-making-kidsunhappy?t=1532525042518, 082017.

5. C. Engel, "Dieser Freiburger Professor baut Handypausen in seine Vorlesungen ein," Badische Zeitung: $\quad$ https://www.badische-zeitung.de/freiburg/dieser-freiburger-professor-baut-handypausen-in-seinevorlesungen-ein-153293341.html, 062018. 